\title{
INTEGRATION OF EVIDENCE-BASED PRACTICE IN BEDSIDE TEACHING PAEDIATRICS SUPPORTED BY E-LEARNING
}

\author{
Jarmila Potomkova*a, Vladimir Mihal $^{\mathrm{b}}$, Jirina Zapletalova ${ }^{\mathrm{b}}$, Dana Subova ${ }^{\mathrm{a}}$ \\ ${ }^{a}$ Palacky University Medical Library, Faculty of Medicine and Dentistry, Palacky University, Olomouc, Czech Republic \\ ${ }^{b}$ Department of Paediatrics, Faculty of Medicine and Dentistry, Palacky University, Olomouc \\ E-mail:potomkov@tunw.upol.cz
}

Received: February 23, 2010; Accepted: March 8, 2010

Key words: Bedside teaching\&learning/Information technology/e-Learning activities/Evidence-based practice/Paediatric curriculum/Web-based learning/Search skills training

Background. Bedside teaching with evidence-based practice elements, supported by e-learning activities, can play an important role in modern medical education. Teachers have to incorporate evidence from the medical literature to increase student motivation and interactivity.

Materials and Methods. An integral part of the medical curricula at Palacky University Olomouc (Czech Republic) are real paediatric scenarios supplemented with a review of current literature to enhance evidence-based bedside teaching \& learning. Searching for evidence is taught through librarian-guided interactive hands-on sessions and/or web-based tutorials followed by clinical case presentations and feedback.

Results. Innovated EBM paediatric clerkship demonstrated students' preferences towards web-based interactive bedside teaching \& learning. In two academic years (2007/2008, 2008/2009), learning-focused feedback from 106 and 131 students, resp. was obtained about their attitudes towards evidence-based bedside teaching. The assessment included among others the overall level of instruction, quality of practical evidence-based training, teacher willingness and impact of instruction on increased interest in the specialty. There was some criticism about excessive workload. A parallel survey was carried out on the perceived values of different forms of information skills training (i.e. demonstration, online tutorials, and librarian-guided interactive search sessions) and post-training self-reported level of search skills.

Conclusion. The new teaching/learning paediatric portfolio is a challenge for further activities, including effective knowledge translation, continuing medical \& professional development of teachers, and didactic, clinically integrated teaching approaches.

\section{INTRODUCTION}

Bedside teaching of medical knowledge, attitudes, and skills plays an important role in modern medical education, even if it dates back to 300 years ago (Silvius, 17 th C., Osler 19 th C. $)^{1,2}$ It is a 3 -stage-process, covering the following steps: introductory phase - "See", practice phase - "Do", and perfecting phase - "Repeat" (ref. $\left.{ }^{3}\right)$. According to the recently published literature ${ }^{4-6}$, it seems appropriate to teach evidence-based practice (EBP) under clinical settings. The process of EBP is based on the pre-requisite that clinicians acquire, locate, evaluate and apply relevant high-quality medical information to a clinical question. Optimally speaking, EBP should comprise collection, interpretation and integration of valid and applicable patient-oriented, clinician-controlled and research-derived knowledge (evidence). Still further, the best available evidence is "brushed up" by patient circumstances and, in particular, preferences to be finally applied to improve the quality of clinical decision-making and facilitate cost-effective care. EBP knowledge and skills can be taught in different ways; either by introducting separate (standalone) courses, or integrating EBP into the existing medical curricula. Teachers must incorporate best evidence from the medical literature into bedside sessions, be aware of their limits and seek information specialist/librarian assistance to train students in getting effective MEDLINE searching skills to retrieve and locate best evidence ${ }^{7}$. The studies describing experience with development of information literacy have shown that if information-related skills are taught by librarians, the teaching process is more authentic and better accepted by students ${ }^{8}$. In general, the whole process requires considerable enthusiasm and committment on the part of both teachers and learners, and last but not least, implementation of information technology to create online interactive curricula to start up e-learning activities.

\section{MATERIALS AND METHODS}

The goal of this paper is to present the results of 3-year (2007-2009) initiatives to integrate principles of evidence-based practice into the undergraduate paediatric curriculum at Palacky University, Faculty of Medicine and Dentistry. The new design followed typical features of a long-proven method of bench-to-bedside teaching ${ }^{9}$. Whenever and wherever possible, students were system- 
atically encouraged to practice evidence-based healthcare procedures around a real-life scenario. Clinical education was suplemented with library-facilitated interactive search skills training to be able to find and interpret a relevant paper, dealing with the problem of the assigned patient. An important part of the project was assessment of the pilot and implementation phases by 106 and 131 students, respectively. The pilot curriculum was evaluated by means of a satisfaction questionnaire, and the officially launched version using a standard evaluation form (6-score-scale: very high - high - ordinary - low - very low - can't tell). The milestone of our efforts was transition from the traditional disease and symptom oriented (DOE) education to patient-oriented evidence that matters (POEM). As an educational intervention, we have been using evidencebased real-life clinical scenarios. For this purpose, we created a more attractive learning environment, in particular broader clinical supervision, support from medical library staff and interactive web-based tutorials.

\section{RESULTS}

\section{Innovation of Curricular Items}

Paediatric Curriculum Framework

\begin{tabular}{|ll|}
\hline Study years: & 4,5 \\
\hline Contact time: & 160 hours \\
\hline Format: & Discipline-based clerkship \\
\hline
\end{tabular}

New Educational Interventions Implemented in StudyYear 5

\begin{tabular}{|l|}
\hline Patient-oriented approach \\
\hline Evidence-based bedside teaching \& learning \\
\hline $\begin{array}{l}\text { Introductory Evidence-based medicine (EBM) } \\
\text { workshop }\end{array}$ \\
\hline Technology-driven information gathering \\
\hline Library-facilitated interactive search skills training \\
\hline $\begin{array}{l}\text { Real case scenario development }+ \text { literature review }+ \\
\text { case presentation }\end{array}$ \\
\hline Self-directed learning \\
\hline $\begin{array}{l}\text { E-learning materials available from education portal } \\
\text { MEFANET }{ }^{10}\end{array}$ \\
\hline
\end{tabular}

The structure of the innovative paediatric curriculum for the 5th year undergraduate students was designed to integrate diferent layers, supporting the main educational goal, in particular real-life case report development. There were several activities to accomplish the task, namely: participation in the introductory EBP workshop, bedside teaching and learning in the paediatric department, formulation of a patient-oriented clinical question and its transformation into a PICO (patient-intervention-com- parison-outcome) format, searching for relevant literature, interpretation of research papers and preparation of discussion. Supplementary educational offerings included interactive search skills training in small groups, and/or librarian-guided information retrieval.

Under careful peer guidance the students completed the patient file, analyzed at least one research paper to answer the assigned clinical question and had a presentation of their case during a min-conference. Their knowledge and skills were assessed by a team of clinician-teachers and librarians as part of the final exam in paediatrics.

Clinical (bedside) teaching of paediatrics was integrated with the principles of evidence based practice. A multiprofessional team, consisting of clinician-teachers, medical librarians, and IT specialists collaborated on developing an online tutorial to support EBP bedside teaching and trigger more effective communication between facilitators and students.

The online EBP paediatric tutorial is characterized by two types of units, i.e. self-learning and facilitated ones, both accesible from the education portal MEFANET (http://mefanet.upol.cz).

\begin{tabular}{|ll|}
\hline Self-Learning Units & \\
\hline $\begin{array}{l}\text { Definition of evidence-based } \\
\text { medicine }\end{array}$ & [Text] \\
\hline Evidence-based medicine process & [Text] \\
\hline $\begin{array}{l}\text { Teaching and learning } \\
\text { evidence-based medicine }\end{array}$ & [Text + graphics] \\
\hline Search tutorials & [Static/Animated] \\
\hline \multicolumn{1}{|c|}{ MEDLINE/PubMed } & [Static] \\
\hline \multicolumn{1}{|c|}{ DYNAMED } & [Static] \\
\hline \multicolumn{1}{|c|}{ UPTODATE } & [Text] \\
\hline $\begin{array}{l}\text { Minimum analysis requirements } \\
\text { for journal articles }\end{array}$ & [Multimedia] \\
\hline $\begin{array}{l}\text { Examples of peer-reviewed } \\
\text { student case reports }\end{array}$ & \\
\hline
\end{tabular}

\section{Facilitated Units}

Model of real-life case report [Presentation] development

Online interactive protocol

for case report development

\section{Student Feedback and Curriculum Assessment}

In academic year 2007/2008 the innovated pilot evidence-based paediatric curriculum was assessed by a group of 106 medical students that completed a satisfaction questionnaire. The results of the survey demonstrated that the new methodology and philosophy was accepted in a positive way by $85 \%$ of the respondents, whilst $15 \%$ had critical and/or negative attitudes. This was a committment for the curricula developers to perform the necessary amendments. 


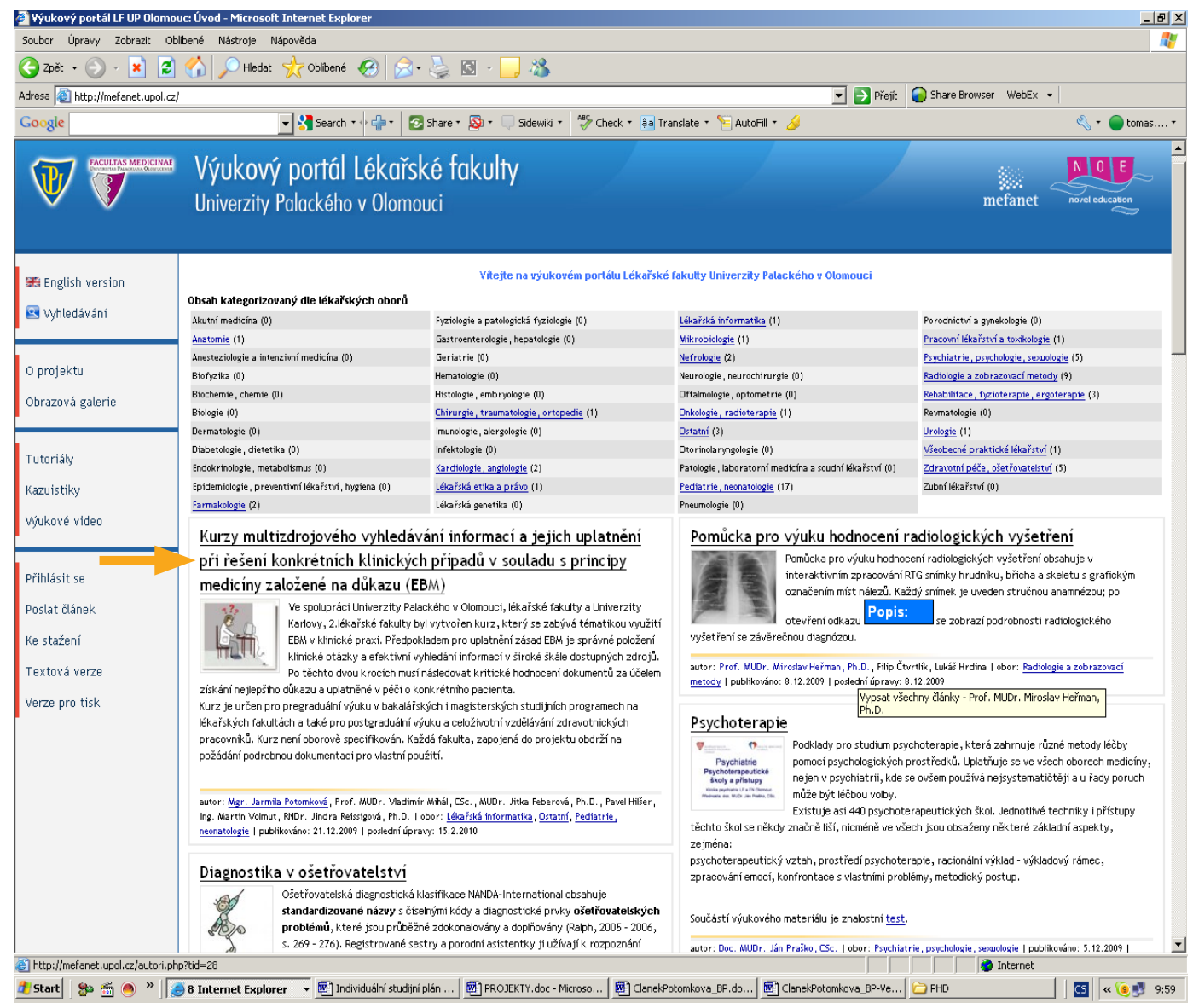

Fig. 1. A webpage of the education portal MEFANET with the EBM tutorial (left column, orange arrow).

In academic year 2008/2009 the innovated curriculum was officially launched and assessed by a total of 131 students who completed the standard evaluation form. The evaluation was performed using a 6-score-scale, where 1 was the best scoring. There was also space for verbatims, and lots of written comments were submitted. The students expressed their opinion, among others, about the following curricular features: overall level of instruction (Fig. 2), value of practical training (Fig. 3), teacher willingness (Fig. 4), and impact of instruction on increassed interest in the specialty (Fig. 5). The results are given in Figs. 2-5 and demonstrate the following best scored instruction features (score 1) by the students (in \%): teacher willingness $(72 \%)$, overall level of instruction ( $55 \%)$, value of practical training (44\%), and impact of instruction on increased interest in the specialty (32\%).

\section{Verbatims}

"I found this learning activity enlivening, illustrating, enriching, BUT extremely time consuming..."

"I think it is a beneficial and contributing element in clinical education, although requiring enormous workload ..."

"For me, it was a waste of time, not a very efficient educational tool...I prefer textbooks."

"In the beginning, I was rather suspicious, because I had no idea what it would be about. Step by step I realized that searching databases is inevitable to find the best treatment option for my young patient. Having completed the clerkship, I decided to become a pediatrician...."

"I especially liked the Introductory EBM workshop, including demonstration of searching for relevant literature."

"I am very happy to be able to search PubMed now, even if the beginnings were very tough. Now I feel competent enough to find what I need.”

\section{Search Skills Survey}

The search skills training survey included a total of 131 students of general medicine that had completed the EBM paediatric clerkship. The students self-reported their post-training level of search skills as high (25\%), average, but satisfactory to accomplish the task (70\%), and low (5\%). The perceived values of instruction (Table 1) were as follows: $82 \%$ of the students valued high the introductory instruction package (presentation about evidence-based practice + non hands-on demonstration how to search for evidence + access to web-based tutorials), whilst $14 \%$ found this insufficient without further interactive search skills training. In principle, $64 \%$ of the respondents considered the subsequent interactive search sessions useful; nonetheless, it was interesting to see that actually $54 \%$ of the students did attend elective interactive training. 
Table 1. Search skills training perceived value ${ }^{13}$ as assessed by 131 respondents that had completed the EBM pediatric clerkship in academic year 2008/2009.

\begin{tabular}{|c|c|c|c|c|c|}
\hline \multirow{2}{*}{ Mode of instruction } & \multirow{2}{*}{$\begin{array}{c}\text { Taught / } \\
\text { Developed by }\end{array}$} & \multirow{2}{*}{ Status } & \multicolumn{3}{|c|}{$\begin{array}{l}\text { Perceived value } \% \\
\qquad(\mathrm{n}=131)\end{array}$} \\
\hline & & & YES & NO & CAN'T TELL \\
\hline $\begin{array}{l}\text { Presentation } \\
+ \text { demonstration } \\
+ \text { web tutorial }\end{array}$ & Clinicians, librarians & Comp & 82 & 14 & 4 \\
\hline $\begin{array}{c}\text { Subsequent } \\
\text { interactive } \\
\text { search skills training }\end{array}$ & Librarians & Elect & 64 & 15 & 21 \\
\hline \multicolumn{3}{|c|}{ Actual attendance } & $54 \%$ & $46 \%$ & $\mathrm{xxx}$ \\
\hline
\end{tabular}

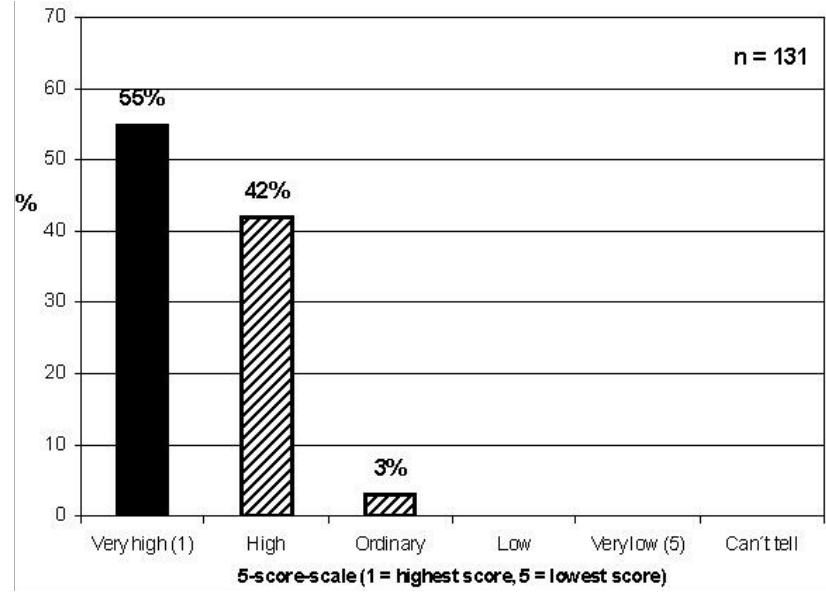

Fig. 2. A curricular feature "Overall level of instruction" as assessed by a total of 131 respondents on a 6-score-scale in academic year 2008/2009.

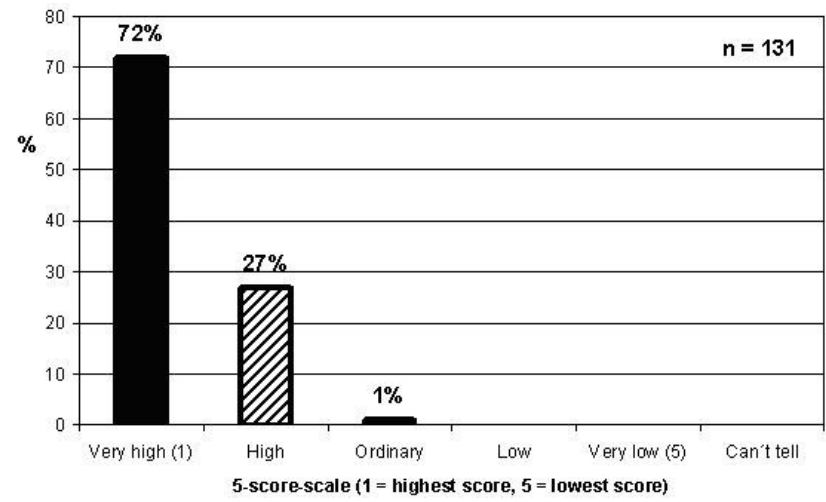

Fig. 4. A curricular feature „Teacher willingnes“ as assessed by a total of 131 respondents on a 6-scorescale in academic year 2008/2009.

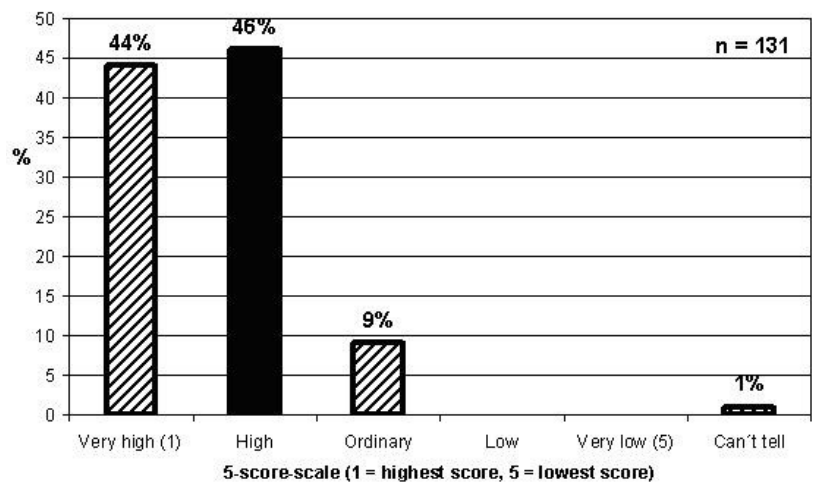

Fig. 3. A curricular feature „Value of practical training“ as assessed by a total of 131 respondents on a 6-score-scale in academic year 2008/2009.

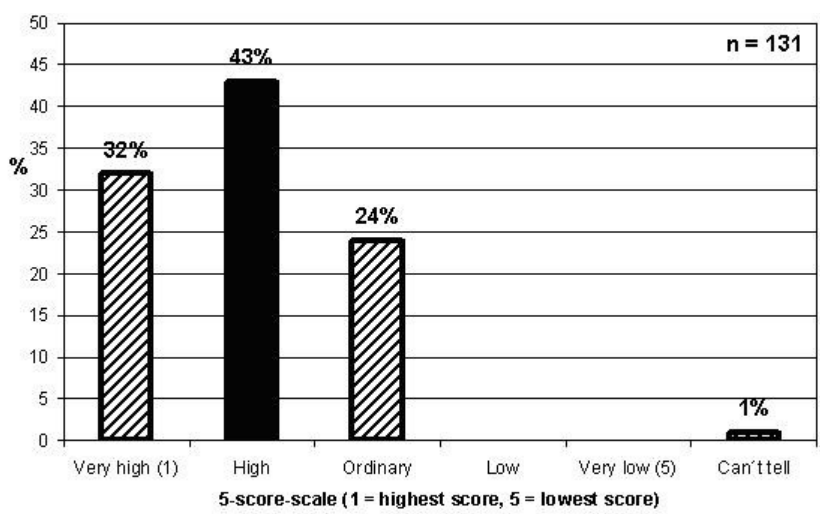

Fig. 5. A curricular feature "Impact of instruction on increased interest in specialty" as assessed by a total of 131 respondents on a 6-score-scale in academic year 2008/2009. 


\section{DISCUSSION}

Student feedback always brings about new issues to consider and inspiration for further improvement of teaching and learning. According to the literature ${ }^{11,12}$ and based on our experience, today's human-computer interaction is becoming a more personalised and adaptable approach than face-to-face classes ${ }^{13}$. However, it still lacks the emotional component; in this context, we have witnessed that our students needed a feeling of being treated in a personal way, a certainty of being guided and supported (personal interviews).

In medical education, dynamic collaboration between clinician-teachers and information specialists can contribute to introduction of principles of evidence-based practice in terms of improvement of bedside teaching and learning by means of searching and using results of the published research for patient benefit ${ }^{14}$. Collaborative instruction is improving the educational environment and offers new teaching tools, eg. interactive sessions taking place in library settings and facilitated by library staff. It is also a good opportunity for making conventional instruction more attractive by developing web-based modules. The final goal of these efforts should be better flexibility of graduates under highly competitive conditions. It is a well-described fact ${ }^{15}$ that active collaboration is based on several principles. First, there should be the same goal and visions on both sides. The second issue is extremely important, because it concerns trust and respect. In particular, it is the allied professions, like librarians and information specialists who have to prove their comptenecies to deserve the respect from clinician-teachers and students. To a certain degree, the roles of medical librarians are irreplaceable which is a pre-requisite for establishing long-term working relationships. The studies describing experience with the development of information literacy skills have shown that if information-related skills are taught by librarians, the teaching process is more authentic and better accepted by students ${ }^{8}$.

It should be admitted that there have been some weeknesses in our project, in particular, short-time experience obtained during one experimental and one implementation year; we have been able to systematically apply evidence based practice to teaching one discipline only; substantial limitations are related to heterogeneous student characteristics, eg. some gaps in epidemiological thinking, various levels of motivation and information technology skills. A most frequently stated obstacle are extra time requirements.

In conclusion, it should be taken into consideration that bedside medical education is a mixture of tradition, art, modern science, technology, and humanity. It is increasing student motivation, if integrated with evidence-based practice, information literacy training, and supported by e-learning activities. Better healthcare requires better medical education. The process of teaching and learning evidence based practice at the bedside is beneficial both for students and teachers. Medical students can see in practice how best evidence is implement- ed at the point of care including the application of the published research and good search skills; these aspects contribute to better motivation for their future jobs. In parallel, clinical teachers become more involved in evidence based practice, their knowledgebase is improving and the exploitation of fee-based institutional information resources is more efficient.

\section{ACKNOWLEDGEMENTS}

The paper reflects the outcomes of Project CZ.04.1.03/3.2.15.2 supported by the European Social Fund and the Budget of the Czech Republic.

The authors appreciate the involvement and enthusiasm of the medical students of Palacky University Faculty of Medicine and Dentistry in academic years 2007/2008 and $2008 / 2009$.

\section{REFERENCES}

1. vanGijn J. Franciscus Silvius (1614-1672). J Neurol 2001; 248(10):915-916.

2. Osler W Sir, Hinohara S, Niki H. Osler's „a way of life“ and other addresses, with commentary and annotations. Duke University Press: 2001.

3. Schwenk TL. CRLT Occasional Paper No.1. Clinical Teaching [Online]. [Cit. 2009-11-10]. Available:http://www.crlt.umich. edu/publinks/occ1.php

1. Kumrow DE. Evidence-based strategies of graduate students to achieve success in a hybrid web-based course. J Nurs Educ 2007; 46(3): $140-145$

2. Schilling K, Wiecha J, Polineni D, Khalil S. An interactive webbased curriculum on evidence-based medicine: design and effectiveness. Fam Med 2006; 38(2):126-132.

3. Khan KS, Coomarasamy A. A hierarchy of effective teaching and learning to acquire competence in evidence-based medicine. BMC Med Edu 2006; 6:59.

4. Bahadorani M, Yousefy AR, Changiz T. Effectiveness of three methods of teaching Medline to medical students: Online, face to face and combined educational methods. IJME 2006; 6(2):35-43.

4. Gross J, Kientz S. Developing information literacy: Collaborating for authentic learning. Teacher Libr 1999; 27(1): 21-21.

5. Turnbull J. Bench to bedside in medical education. Acad Med 1999; 74:664-666.

6. MEFANET [Online]. c2007. Updated September 2009. [Cit. 2009-11-10]. Available: http://mefanet.upol.cz

7. Pivec M, Baumann K. The role of adaptation and personalisation in classroom-based learning and in e-learning. J Univ Comp Sci 2004; 10(1):73-89.

8. Koc M, Individual learner differences in web-based learning environments: from cognitive, affective and social-cultural perspectives. Turk Online J Dist Educ-TOJDE 2005; 6(4):A2.

9. Ledden L, Kalafatis SP, Samouel P. The relationship between personal values and perceived value of education. J Bus Res 2007; 60(9): 965-974.

10. Straus S, Haynes RB. Managing evidence-based knowledge: the need for reliable, relevant and readable resources. CMAJ 2009;180(9): 942-948.

11. Callison D. Keywords in instruction: Collaboration. School Libr Media Act Monthly 1999;15(5):38-40. 
